\title{
PHYSIOLOGICAL EFFECTS OF PERINATAL STRESS ON HYPOTHALAMIC- PITUITARY-ADRENAL (HPA) AXIS IN RAT PUPS WITH MODEL OF HYPERTHYROIDAL MOTHERS
}

\author{
SOTOHY A. SOTOHY ${ }^{1}$, KHALED A. ABDEL-SATER ${ }^{2}$, MOHAMED A. MAHMOUD ${ }^{3}$ \\ MAHMOUD ABD-ELKAREEM MAHMOUD ${ }^{4}$ and ASMAA H. ABDEL-KAREEM ${ }^{5}$ \\ ${ }^{1}$ Department of Animal Hygiene, Faculty of Veterinary Medicine, New Valley University, Egypt. \\ ${ }^{2}$ Department of Physiology, Faculty of Medicine, Al Azhar University Assiut, Egypt, \\ ${ }^{3}$ Department of Physiology, Faculty of Veterinary Medicine, New Valley University, Egypt, \\ ${ }^{4}$ Department of Anatomy, Embryology \& Histology, Faculty of Veterinary Medicine, Assiut University, Egypt, \\ ${ }^{5}$ Department of Physiology, Faculty of Veterinary Medicine, New Valley University, Egypt.
}

Received: 30 December 2018; Accepted: 21 January 2019

\begin{abstract}
Hyperthyroidism is common endocrine problem encountered in pregnancy. It is well known that hyperthyroidism induces an increase in the activity of hypothalamic- pituitary - adrenal (HPA) axis. There are a few reports about development of the HPA axis in rat pups of hyperthyroid mothers. Therefore, this study was designed to investigate that maternal hyperthyroidism during pregnancy impaired feedback mechanisms of the HPA- axis and associated with thyroid disorders and neurobiological alterations in off sprigs. Therefore, 30 female wistar rats (200-250gm) after induction of pregnancy and hyperthyroxinemia. Their pups were divided into six groups (control non stressed group, hyperthyroid non stressed group, treated non stressed group, control stressed group, hyperthyroid stressed group, treated stressed group). Measurement of some hormones and histological analyses were done and result the induction of hyperthyroidism in mothers was significantly increased of plasma $\mathrm{T}_{4}$ and decreased of plasma TSH levels in all pups group compared with control group. ACTH and Corticosterone increased in stressed group compared with other group. In addition hyperthyroid group showed small amount of colloid with irregular structure and architecture of the thyroid gland compared with treated and control group. In conclusion, the effects of maternal stress exposure during pregnancy on HPAaxis regulation and anxiety-like behavior can be transferred via the maternal line to the its offspring's.
\end{abstract}

Key words: Hyperthyroidism, pregnancy, stress, HPA axis.

\section{INTRODUCTION}

Thyroid hormones (THs) play a crucial role in the development and physiological function of different body organs especially the brain. Thus, any vigorous changes in the THs levels during the development may cause a patho-physiological states and serious damage to the structural development and organization of the brain (Ahmed, 2015).

Hyperthyroidism is common endocrine disease with pregnancy. It affects on the thyroid gland by changing the size and amount of secretion hormones. Thyroid hyperstimulation, caused by human chorionicgonadotrophin (hCG) at the end of the first trimester (Michaelson-chohen et al., 2008). Requirement of dietary iodine increased which is stimulant factor for synthesis of thyroid hormone these is another physiological change during pregnancy (Bianco and Kim, 2006).

Corresponding author: Asmaa Hussein Abd El-Kareem E-mail address: asmaah7592@gmail.com

Present address: Demonstrator at Department of Physiology, Faculty of Vet. Medicine, New Valley University
Uncontrolled hyperthyroidism in pregnancy induced hypertension, preterm delivery and even heart failure. Pups complications include intrauterine growth retardation, prematurity, still birth, low birth weight and postnatal death. In turn, hyperthyroidism in pregnancy is usually associated with Graves' disease (luton et al., 2005). Medical treatment in hyperthyroid pregnant women is the management of choice (Kennedy et al., 2010).

Thyroid diseases that can affect the newborn infants of mothers with Graves' disease include hyperthyroidism in the infants caused by the passage of stimulant antibodies from the placenta to the fetus which interferes with the development of the thyroid and changes the pituitary feedback that regulates thyrotropin secretion. (Schetter and Tanner, 2012). Altered HPA axis function is supposed to have a vital role programming of disease risk (Frodl, 2013). Many authors (Meserve, 1985) stated that rat HPA show stress hypo-response during the period of 4 to 14 of age, by the day 15 of age and on word, the corticosterone level increase until reaching the adult level. Schmidt et al. (2004) attributed this decrease 
in response to the adrenal gland itself, whereas the neuroendocrine stress axis, such as the corticotrophin releasing hormone $(\mathrm{CRH})$, is a stress responsive. So the aim of the current work is to investigate the effect of treatment of the hyperthyroxinemia as a model of hyperthyroidal mother on development of HPA-axis of their pups.

\section{MATERIALS AND METHODS}

\section{Materials}

\section{Drugs and chemicals}

Thyroxine 98 free base was purchased from Sigma Aldrich, UK. It was present as a clear faintly white powder in a brown bottle. Carbimazole and other fine chemicals were obtained from Sigma Chemical Company, St. Louis, USA. Thyroxine, adrenocorticotropichormone, cortisone and thyrotropin hormone kits were purchased from Egyptian Company for Biotechnology.

\section{Site of Study}

This experiment performed in animal house of the Faculty of Medicine, Assuit University.

\section{Experimental animals}

Thirty mature adult female albino rats (30) of Wistar strain weighting (200-250 g) were purchased from animal house of the Faculty of Medicine, Assuit University (Egypt). Rats were housed in stainless steel cages; each cage was $25 \times 25 \times 30 \mathrm{~cm}$. The room was kept at $24^{\circ} \mathrm{C}$ with controlled humidity, and maintained under light/dark cycles consisting of $12 \mathrm{~h}$ of light and $12 \mathrm{~h}$ of dark cycle. They were fed a standard commercial pellet diet and water throughout the experimental period. All rats were kept isolated for two weeks in the laboratory room at comfortable room temperature for adaptation before any experiment. All experiments were performed during the same time of day, between 8 a.m and 2 p.m to avoid variations due to diurnal rhythms. Manipulations throughout test were carried out by the same person (Shimizu et al., 2000). All experimental procedure were conducted according to the Ethical Guidelines for investigations of experimental pain in conscious animals (Zimmermann, 1983).

\section{Experimental protocol}

Group I (control group): Normal pups from mothers with normal $\mathrm{T}_{4}$ levels.

Group II (treated group): Pups with treated hyperthyroidal model mother.

And group III (nontreated group): Pups with nontreated hyperthyroidal model mother.

There are 2 subgroups from rat pups of each of the above three groups; stress group and nonstress group.

\begin{tabular}{lll}
\hline Control group & Hyperthyroid group & Treated group \\
\hline Non $\operatorname{stress}(\mathrm{n}=5)$ & Non $\operatorname{stress}(\mathrm{n}=5)$ & Non stress $(\mathrm{n}=5)$ \\
$\operatorname{stress}(\mathrm{n}=5)$ & $\operatorname{stress}(\mathrm{n}=5)$ & $\operatorname{stress}(\mathrm{n}=5)$ \\
\hline
\end{tabular}

\section{Methods}

\subsection{Induction of pregnancy:}

Daily examination of vaginal smear of each virgin female was carried out to determine the estrus cycle. Estrous females exhibited the presence of cornified cells in vaginal smear. Mating was induced by housing proesterous females with male in separate cage at ratio of two females and one male overnight for 1 or 2 consecutive days. In the next morning, the presence of sperm in vaginal smear determined the first day of gestation (GD1). Then, the pregnant females were transferred in to separate cages from males to start the experiment (Hapon et al., 2003).

Pregnant mothers were divided in to 3 groups (control, hyperthyroid or non treated, and treated group).

$\mathrm{n}=10$ for each group
2.2 Induction of hyperthyroxinemia (as model of hyperthyroidism mother of wistar rat):

This started directly after mating (GD1-GD14) (Abdel-Moneim, 2005). Hyperthyroxinemia was induced by daily intraperitoneal injections of Lthyroxin $25 \mu \mathrm{g} / 100 \mathrm{~g}$ body weight for 14 days $(n=10)$. L-thyroxin was dissolved in saline solution immediately before injection. Control rats were received daily intraperitoneal injections of saline solution for same 14 days. The success of induction of hyperthyroidism was confirmed by determination the elevation of plasma T4 levels in hyperthyroidism group in comparison with control group (Bruno et al., 2005).

\subsection{Induction of Treatment:}

The treated group rats $(\mathrm{n}=10)$ were administered $20 \mathrm{mg} / \mathrm{kg} /$ day carbimazole orally from GD 15 to end of experiment. Control rats were received distilled water. The administration of treatment was 
continued even during lactation. The fetus were accessed to the drug by placenta transfer and pups through milk secretion (Hasebe et al., 2008).

\subsection{Labour and Pups Experimental Groups:}

At day 3 before delivery the rats caged individually. The maternal animals allowed delivering pups naturally. The date of birth designated day 0 (= postnatal day $0=$ pnd 0$)$. On pnd 1 , litters were housed with their mothers in separate cages. There is no significant effect of sex on HPA axis response, so individual pups were used as the unit of analysis (Mastorakos et al., 2007).

\subsection{Stress Procedure:}

The prenatal restraint stress (PRS) procedure were done in hyperthyroid and treated groups $(n=20)$ which consisted in restraining the pregnant mother rat in a transparent Plexiglas cylinder, 3 times/day for 45 min under bright light at GD 14 until delivery at 21-22 days (Morley-Fletcher et al., 2003).

After delivery Pups of stressed group ( $\mathrm{n}=15)$ subjected to restraint by fixing the four limbs to a wooden board and placed in a refrigerator at $4^{\circ} \mathrm{C}$ for three hours, and the process were repeated every day for 8 days. Control group still in cages not exposed to stress (Bhatnagar et al., 1998).

\section{N.B : Mortality Rates:}

The rats pups didn't die in the normal control group $0 \%$, where as three rats pups died in group with hyperthyroid group (stress) with mortality rate $30 \%$. Two rats pups died in the treated group (stress) with mortality rate $20 \%$.

\subsection{Collection of Blood Samples:}

The pups were anaesthetized with ether by placing the rat in an anesthetic box filled with ether vapor which was maintained by periodically applying liquid ether to a cotton wool on the base of the box. When surgical stage of anesthesia was reached (judged by loss of withdrawal reflexes) the animal was removed and placed on a table. Intracardiac samples of blood were collected individually in labeled $1.5 \mathrm{ml}$ ethylenediametetra acetic acid (EDTA) tube at the time of decapitation. Plasma was separated by centrifugation at 3000 r.p.m. for 15 minutes at room temperature and kept in deep freeze at $-70^{\circ} \mathrm{C}$ (Schmidt et al., 2002). Until assayed for T4, TSH, ACTH and corticosterone.

\subsection{Histopathological Examination:}

The thyroid gland of each rat dissected out and fixed in $10 \%$ formalin solution dehydrated in ascending grades of alcohol, cleared, embedded in paraffin and serially sectioned $(8 \mu \mathrm{m})$. Sections were stained with Haematoxilin and Eosin stain (H\&E).

\subsection{Hormonal Analysis:}

a- Measurement of Plasma Thyroxine (T4) Levels:

Plasma T4 levels were determined using the enzyme -linked immunosorbent assay (ELISA), according to (Thienpont et al., 1994).

\section{b- Measurement of Plasma Thyrotropin (TSH) Levels: \\ Plasma TSH levels were determined using the enzyme -linked immunosorbent assay (ELISA), according to (Nicoloff and Spencer, 1990).}

c- Measurement of Plasma Adrenocorticotropic Hormone (ACTH) levels:

Plasma ACTH levels were determined using the enzyme -linked immunosorbent assay (ELISA), according to (Arlt and Stewart, 2005).

\section{d- Measurement of Plasma Corticosterone Levels:}

Plasma corticosterone levels were determined by the enzyme-linked immunosorbent assay (ELISA), according to the manufacturer's instructions (ENZO, USA) (Balaji, 2013).

\subsection{Statistical Analyses:}

The data were submitted to one-way analysis of variance (ANOVA) followed by Duncan 's post hoc test considering $\mathrm{P}<0.05$ using SPSS 11,0 software (SPSS Inc, Chicago, IL, 2001), results were expressed as mean \pm S.E.

\section{RESULT}

\section{Histopathological Changes:}

The present study revealed that in the hyperthyroidism- like group the amount of colloid decreased (sparse pale colloid) and the height and activity of the follicular epithelium increased, whereas in the treated group the amount of colloid increased (abundant acidophilic colloid) and the height and activity of the follicular epithelium decreased. 


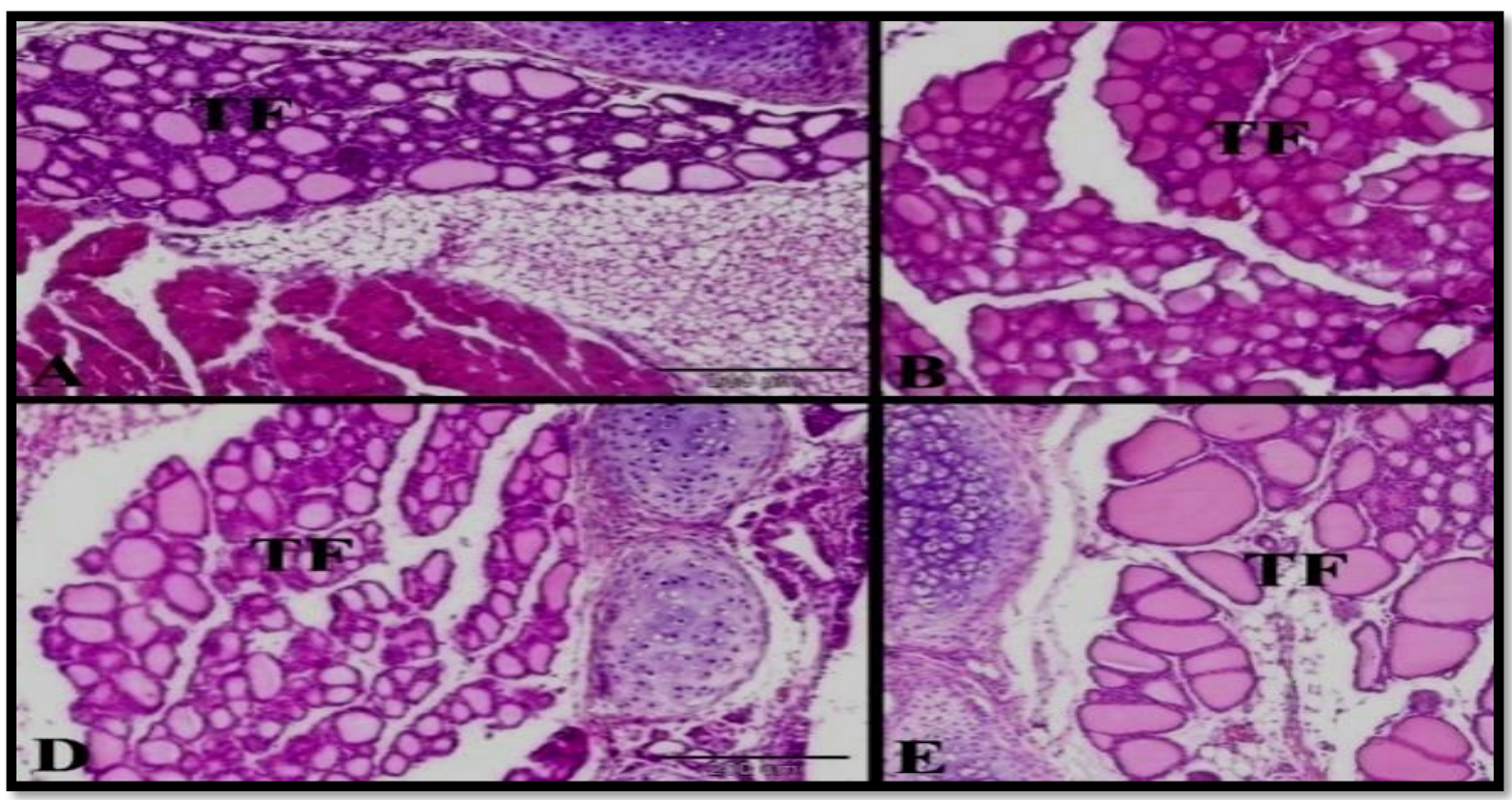

Fig. (1): Photomicrograph of paraffin sections in thyroid gland in rat pups; A; control non-stressed group (pups of normal mothers), B; control stressed group (pups of stressed non-treated hyperthyroidal mothers), C; hyperthyroidism non-stressed group (pups of non-stressed hyperthyroidal mothers), D; hyperthyroidism stressed group (pups of stressed hyperthyroidal model mothers), E; treated non-stressed group (pups of treated nonstressed hyperthyroidal mothers) and F; treated stressed group (pups of treated stressed hyperthyroidal mothers). Fig. A; showing normal structure of the thyroid gland; Lobulated parenchyma formed of regular shaped (rounded or oval) and size thyroid follicles (TF). Fig. B, showing Lobulated parenchyma formed of irregular shape and size thyroid follicles (TF). Fig. C, showing enlarged hypertrophied parenchyma formed of irregular large sized thyroid follicles (TF). Fig. D, showing enlarged parenchyma formed of irregular large sized thyroid follicles (TF). Fig. E \& F showing slightly enlarged parenchyma formed of large sized thyroid follicles (TF). Original magnification, $100 \mathrm{X}$, scale bar $=200 \mu \mathrm{m}$, Hematoxylin and Eosin stain.

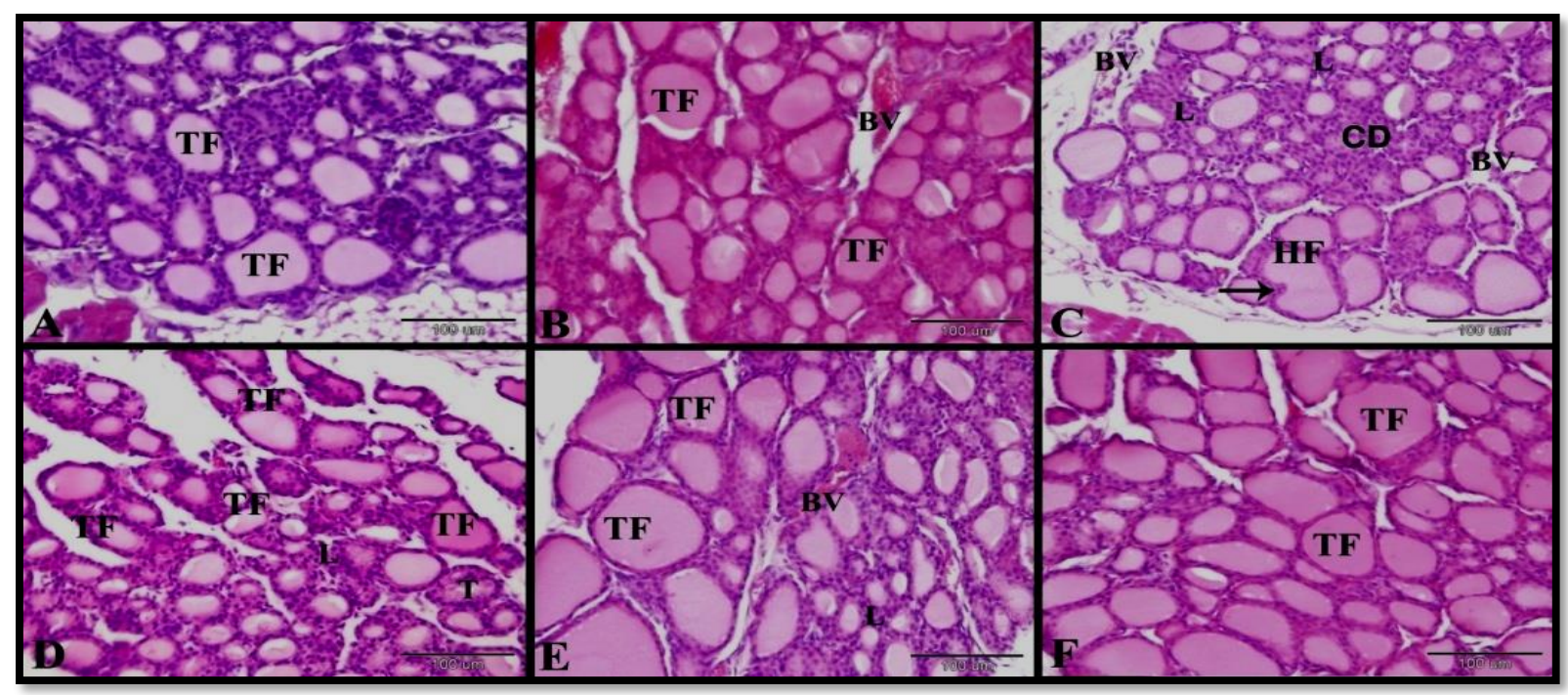

Fig. (2): Photomicrograph of paraffin sections in thyroid gland in rat pups; A; control non-stressed group showing normal rounded or oval thyroid follicles (TF). B; control stressed group showing acidophilic thyroid follicles and congested blood vessels (BV). C; hyperthyroidism non-stress group showing hyperplastic thyroid follicles (HF) with papillary in foldings (arrow), congested blood vessels (BV), increased cellular density (CD) and lymphocytic infiltration (L). D; hyperthyroidism stressed group showing irregular thyroid follicles (TF) some with tall columnar cells $(\mathrm{T})$ and lymphocytic infiltration (L). E; treated non-stressed group showing enlarged hypertrophied thyroid follicles (TF) and congested blood vessels (BV). F; treated stressed group showing slightly hypertrophied thyroid follicles (TF). Original magnification, 200X, scale bar=100 $\mu \mathrm{m}(\mathrm{H} \& \mathrm{E})$ stain. 


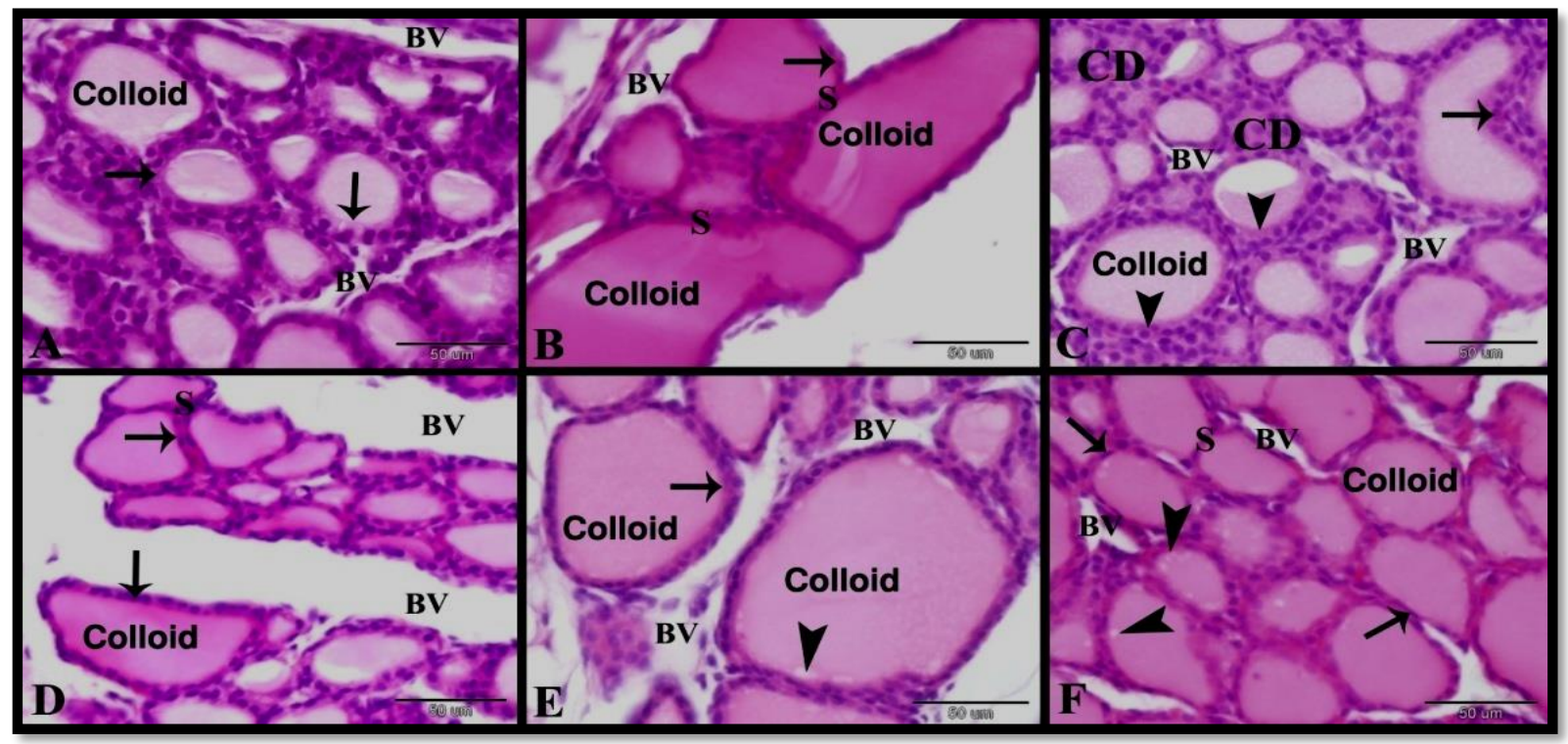

Fig. (3): Photomicrograph of paraffin sections in thyroid gland in rat pups; A; control non-stressed group showing normal thyroid follicles with lightly stained acidophilic colloid and cuboidal follicular cells (thyrocytes) (arrow), the follicles separated by blood vessels (BV). B; control stressed group showing hypertrophied thyroid follicles with flattened follicular cells (arrow), abundant deeply stained acidophilic colloid and thin interfollicular septum (S), the follicles separated by wide blood vessels (BV). C; hyperthyroidism non-stress group showing hyperplastic thyroid follicles with papillary in foldings (arrow) and lined by cuboidal to columnar follicular cells (arrow head), foamy vacuolated lightly stained acidophilic colloid, increased cellular density (CD) and blood vessels (BV). Note, the papillary in foldings had no fibrovascular cores. D; hyperthyroidism stressed group showing irregular thyroid follicles lined by flattened follicular cells (arrow) and contained acidophilic colloid, the follicles separated by wide blood vessels (BV) and thin interfollicular septum (S), E; treated non-stress group showing enlarged hypertrophied thyroid follicles with low cuboidal follicular cells (arrow) and contained moderate amount of acidophilic colloid with peripheral scalloping (arrow head), the follicles separated by numerous blood vessels (BV). F; treated stressed group showing slightly hypertrophied thyroid follicles with flattened follicular cells (arrow) and contained abundant acidophilic colloid with peripheral scalloping (arrow head), the follicles separated by numerous blood vessels (BV) and had thin interfollicular septum (S). Original magnification, 400X, scale bar $=50 \mu \mathrm{m}$, Hematoxylin and Eosin stain.

\section{Hormonal Changes}

\subsection{Measurement of T4 and TSH Hormones in} Rats Pups with Hyper thyroidal Model Mothers. The obtained data (table1) revealed that the induction of hyperthyroidism in rat's mothers significantly $(\mathrm{p}<0.05)$ increased the plasma $\mathrm{T}_{4}$ and decreased plasma TSH levels compared to control group. Plasma $\mathrm{T}_{4}$ levels showed marked increase in hyperthyroidal mother's stressed and non-stressed group compared to other animal's groups. Treated stressed animal's groups revealed significant $(\mathrm{p}<0.05)$ decline compared to the hyperthyroid (stressed and non-stressed). Regarding to the TSH, animals with hyperthyroidism (stressed and nonstressed) reported noticeable hormone plasma concentration decreases compared to the control non-stressed and treated non-stressed groups.
2.2 Measurement of ACTH and Corticosterone Hormones in Rats Pups with Hyperthyroidal Model Mothers

The study presented here has shown that the ACTH plasma concentration (table:1) reported marked increases $(p<0.05)$ in hyperthyroidism (stress and non-stressed) compared to the control groups, the treated animas groups showed marked decreases in the level of ACTH compared to the hyperthyroidism animal group. Corticosterone plasma concentrations indicated significant $(\mathrm{p}<0.05)$ decrease in the hyperthyroidism-stressed groups compared to the control groups. Treated non-stress animal groups showed clear reduction in the corticosterone plasma concentration. 
Table 1: Show effect of maternal model hyperthyroidism and stress on plasma T4, TSH, ACTH and Corticosterone of their pup.

\begin{tabular}{ccccccc}
\hline Groups & $\begin{array}{c}\text { Control } \\
\text { (non- stress) }\end{array}$ & $\begin{array}{c}\text { Control } \\
\text { (stress })\end{array}$ & $\begin{array}{c}\text { Hyperthyroidism } \\
\text { (non-stressed) }\end{array}$ & $\begin{array}{c}\text { Hyperthyroidism } \\
\text { (stressed) }\end{array}$ & $\begin{array}{c}\text { Treated } \\
\text { (non-stressed) }\end{array}$ & $\begin{array}{c}\text { Treated } \\
\text { (stressed) }\end{array}$ \\
\hline $\mathrm{T}_{4}(\mathrm{ng} \%)$ & $4.16 \pm 0.26^{\mathrm{cd}}$ & $3.424 \pm 0.06^{\mathrm{cd}}$ & $10.52 \pm 1.43^{\mathrm{a}}$ & $6.42 \pm 0.46^{\mathrm{b}}$ & $5.13 \pm 0.39^{\mathrm{bc}}$ & $2.92 \pm 0.28^{\mathrm{d}}$ \\
\hline $\mathrm{TSH}(\mathrm{ng} \%)$ & $0.20 \pm .055^{\mathrm{b}}$ & $0.005 \pm 0.001^{\mathrm{c}}$ & $0.037 \pm 0.011^{\mathrm{c}}$ & $0.003 \pm 0.001^{\mathrm{c}}$ & $0.35 \pm 0.06^{\mathrm{a}}$ & $0.10 \pm 0.02^{\mathrm{c}}$ \\
\hline $\mathrm{ACTH}(\mathrm{pg} / \mathrm{ml})$ & $4.58 \pm 0.78^{\mathrm{c}}$ & $10.90 \pm 1.18^{\mathrm{b}}$ & $8.98 \pm 0.72^{\mathrm{b}}$ & $14.24 \pm 0.82^{\mathrm{a}}$ & $5.04 \pm 0.96^{\mathrm{c}}$ & $11.00 \pm 0.69^{\mathrm{b}}$ \\
\hline $\begin{array}{c}\text { Corticosterone } \\
(\mu \mathrm{d} / \mathrm{dl})\end{array}$ & $4.36 \pm 0.50^{\mathrm{a}}$ & $8.32 \pm 0.69^{\mathrm{c}}$ & $7.98 \pm 0.63^{\mathrm{c}}$ & $15.90 \pm 1.13^{\mathrm{a}}$ & $4.30 \pm 0.48^{\mathrm{a}}$ & $12.52 \pm 1.12^{\mathrm{b}}$ \\
\hline
\end{tabular}

Means label different superscript letter at the same row are significantly $(\mathrm{p}<0.05)$ different

\section{DISCUSSION}

The main findings of the present study indicate that stress applied to pregnant dams during gestation associated with hyperthyroidism produces adverse effect on an offspring that might be related to HPA axis.

Blood concentration of thyroxin hormones physiologically changes during pregnancy, these variation occurs due to placental hormones like hCG which has TSH like effect that mildly stimulate the thyroid gland for thyroxin production and estrogen which produces higher levels of thyroid- binding globulin that helps in transport of thyroid hormone in blood (Visser, 2018). Several reports have described the basic role of the thyroid hormones on the development of mammalian and non-mammalian brain (Horn and Heuer, 2010). Other reports have described the harmful effect of hypo- or hyperthyroidism affects the maturation of the CNS system and causes irreversible dysfunction of the brain if not corrected shortly after the birth (Ahmed et al., 2008). Hyperthyroidism in pregnancy is associated with adverse maternal, obstetrical and fetal outcome (Aggarawal et al., 2014). In the present study L-thyroxin $25 \mu \mathrm{g} / 100 \mathrm{~g}$ body weight was used to induce hyperthyroidism to the rat with daily intraperitoneal injections for 14 days. This method previously used by $\mathrm{Wu}$ et al. (2011) and $\mathrm{Yu}$ et al. (2015). In the present work, the induction of hyperthyroidism in mothers was significantly increased of serum T4 and decreased of serum TSH levels in all pups groups compared with control groups. These results are agree with Karnath et al. (2004) who reported that tissue effects of hyperthyroidism include accelerated metabolism, low serum cholesterol, increased bone turnover, reduced bone density with an increased risk of osteoporosis and suppressed serum TSH and Leung (2012) who found that hyperthyroidism strongly is associated with lower TSH values and the elevation in total T4 and total T3 in the first trimester of gestation. Thyroid hormone production is regulated by TSH hormone, which is made by the pituitary gland in the brain. When thyroid hormone levels in the blood are low, the pituitary releases more TSH. When thyroid hormone levels are high, the pituitary responds by decreasing TSH production (PatilSisodia and Mestman, 2009). The obtained data in this study revealed that stress reduced plasma T4, TSH levels compared with non stressed group. The serum levels of T4 and TSH were significantly increased in hyperthyroid non stressed group compared with hyperthyroid stressed group. This result consistent with (Helmreich et al., 2005) who stated that; during stress the level of T3 and T4 were decreased moreover due to the action of glucocorticoids on CNS, stress also inhibits TSH hormone secretion. Hyperthyroidism has been associated with hyperactivity of the hypothalamicpituitary-adrenal (HPA) axis (Johnson et al., 2005). In the present study, PRS can lead to anxiety-like behavior during the adolescent period. These results are in agreement with Maccari and Morley-Fletcher (2007), Zuena et al. (2008) and Rayen et al. (2011).

Chen et al. (2012) reported that exposure to stress during early development causes long-lasting alterations in behavior and HPA-axis activity, including increased expression of $\mathrm{CRH}$, these previous findings confirm the current work results that revealed similar pattern regarding to the hypothalamus $\mathrm{CRH}$ and plasma corticosterone response to acute restraint stress. These findings matched the findings of King et al. (2001) who reported that in human pregnancy, regulation of the 
HPA-axis dramatically changes with the production and release of placental cortisol.

\section{CONCLUSION}

The present study revealed that the effects of maternal stress exposure during pregnancy on HPAaxis regulation and anxiety-like behavior can be transferred via the maternal line to the its offspring's. Stress lead to various changes in the hormones level, these changes may lead to various immunological and endocrine disorders.

\section{of interest}

Authors declare that there is conflict of interest.

\section{REFERENCES}

Abdel-moneim, A. (2005): Effects of repaglinide administration on some biochemical and oxidative stress parameters of diabetic and hyperthyroid albino rats. J. Egypt. Ger. Soc. Zool. Comp. Physiol, 46, 1-29.

Aggarawal, N.; Suri, V.; Singla, R.; Chopra, S.; Sikka, P.; Shah, V.N. and Bhansali, A. (2014): Pregnancy outcome in hyperthyroidism: a case control study. Gynecologic and obstetric investigation, 77, 94-99.

Ahmed, O.M.; EL-Gareib, A.; EL-Bakry, A.; ELTawab, S.A. and Ahmed, R. (2008): Thyroid hormones states and brain development interactions. International Journal of Developmental Neuroscience, 26, 147-209.

Ahmed, R. (2015): Maternofetal thyroid action and brain development. Journal of Advances in Biology, 7, 1207-1213.

Arlt, W. and Stewart, P.M. (2005): Adrenal corticosteroid biosynthesis, metabolism, and action. Endocrinology and Metabolism Clinics, 34, 293-313.

Balaji, K. (2013): Effect of Different Bedding Materials on the Performance of Rats. Karnataka Veterinary, Animal and Fisheries Sciences University, Bidar 82-401.

Bhatnagar, S.; Dallman, M.F.; Roderick, R.E.; Basbaum, A.I. and Taylor, B.K. (1998): The effects of prior chronic stress on cardiovascular responses to acute restraint and formalin injection. Brain research, 797, 313-320.

Bianco, A.C. and Kim, B.W. (2006): Deiodinases: implications of the local control of thyroid hormone action. The Journal of clinical investigation, 116, 2571-2579.

Bruno, A.N.; Diniz, G.P.; Ricachenevsky, F.K.; Pochmann, D.; Bonan, C.D.; Barreto-chaves, M.L.M. and Sarkis, J.J.F. (2005): Hypo-and hyperthyroidism affect the ATP, ADP and AMP hydrolysis in rat hippocampal and cortical slices. Neuroscience research, 52, 61-68.

Chen, J.; Evans, A.N.; LIU, Y.; Honda, M.; Saavedra, J.M. and Aguilera, G. (2012): Maternal deprivation in rats is associated with corticotrophin-releasing hormone (CRH) promoter hypomethylation and enhances $\mathrm{CRH}$ transcriptional responses to stress in adulthood. Journal of neuroendocrinology, 24, 1055-1064.

Frodl, A. (2013): Betriebsführung im Gesundheitswesen, Springer Fachmedien Wiesbaden.

Hapon, M.; Simoncini, M.; VIA, G. and Jahn, G. (2003): Effect of hypothyroidism on hormone profiles in virgin, pregnant and lactating rats, and on lactation. Reproduction, 126, 371-382.

Hasebe, M.; Matsumoto, I.; Imagawa, T. and Uehara, M. (2008): Effects of an anti-thyroid drug, methimazole, administration to rat dams on the cerebellar cortex development in their pups. International Journal of Developmental Neuroscience, 26, 409-414.

Helmreich, D.L.; Parfitt, D.; LU, X.-Y.; Akil, H. and Watson, S. (2005): Relation between the hypothalamic-pituitary-thyroid (HPT) axis and the hypothalamic-pituitary-adrenal (HPA) axis during repeated stress. Neuroendocrinology, 81, 183-192.

Horn, S. and Heuer, H. (2010): Thyroid hormone action during brain development: more questions than answers. Molecular and cellular endocrinology, 315, 19-26.

Johnson, E.O.; Kamilaris, T.C.; Calogero, A.E.; Gold, P.W. and Chrousos, G.P. (2005): Experimentally-induced hyperthyroidism is associated with activation of the rat hypothalamic-pituitary-adrenal axis. European journal of endocrinology, 153, 177-185.

Karnath, B.M.; Beary, W.M.; Ahmad, M. and Mckinney, K.H. (2004): Thyrotoxicosis presenting as pulmonary hypertension. Journal of Respiratory Diseases, 25, 387-390.

Kennedy, R.; Malabu, U.; Jarrod, G.; Nigam, P.; Kannan, K. and Rane, A. (2010): Thyroid function and pregnancy: before, during and beyond. Journal of obstetrics and gynaecology, 30, 774-783.

King, B.R.; Nicholson, R.C. and Smith, R. (2001): Placental Cortieotrophin-releasing Hormone, Local Effects and Fetomaternal Endocrinology. Stress, 4, 219-233.

Leung, A.M. (2012): Thyroid function in pregnancy. Journal of Trace Elements in Medicine and Biology, 26, 137-140.

Luton, D.; LE gac, I.; Vuillard, E.; Castanet, M.; Guibourdenche, J.; Noel, M.; Toubert, M.-E.; Leger, J.; Boissinot, C. and Schlageter, M.-H. 
(2005): Management of Graves' disease during pregnancy: the key role of fetal thyroid gland monitoring. The Journal of Clinical Endocrinology \& Metabolism, 90, 6093-6098

Maccari, S. and Morley-fletcher, S. (2007): Effects of prenatal restraint stress on the hypothalamus-pituitary-adrenal axis and related behavioural and neurobiological alterations. Psychoneuroendocrinology, 32, S10-S15.

Mastorakos, G.; Karoutsou, E.I.; Mizamtsidi, M. and Creatsas, G. (2007): The menace of endocrine disruptors on thyroid hormone physiology and their impact on intrauterine development. Endocrine, 31, 219-237.

Meserve, H.C. (1985): The importance of ignorance. Journal of Religion \& Health, 24, 267-271.

Michaelson-cohen, R.; Altarescu, G.; Beller, U.; Reens, R.; Halevy-shalem, T. and Eldar-geva, T. (2008): Does elevated human chorionic gonadotropin alone trigger spontaneous ovarian hyperstimulation syndrome? Fertility and sterility, 90, 1869-1874.

Morley-fletcher, S.; Darnaudery, M.; Koehl, M.; Casolini, P.; Van reeth, $O$. and Maccari, S. (2003): Prenatal stress in rats predicts immobility behavior in the forced swim test: effects of a chronic treatment with tianeptine. Brain research, 989, 246-251.

Nicoloff, J.T. and Spencer, C.A. (1990): The use and misuse of the sensitive thyrotropin assays. The Journal of Clinical Endocrinology \& Metabolism, 71, 553-558.

Patil-sisodia, K. and Mestman, J. (2009): Graves hyperthyroidism and pregnancy: a clinical update. Endocrine Practice, 16, 118-129.

Rayen, I.; Van den hove, D.L.; Prickaerts, J.; Steinbusch, H.W. and Pawluski, J.L. (2011): Fluoxetine during development reverses the effects of prenatal stress on depressive-like behavior and hippocampal neurogenesis in adolescence. PloS one, 6, e24003.

Schetter, C.D. and Tanner, L. (2012): Anxiety, depression and stress in pregnancy: implications for mothers, children, research, and practice. Current opinion in psychiatry, $25,141$.

Schmidt, M.; Enthoven, L.; Van woezik, J.; Levine, S.; De kloet, E. and Oitzl, M. (2004): The Dynamics of the Hypothalamic-
Pituitary-Adrenal Axis During Maternal Deprivation. Journal of neuroendocrinology, $16,52-57$.

Schmidt, M.; Okimoto, D.; Dent, G.; Gordon, M. and Levine, S. (2002): Maternal regulation of the hypothalamic-pituitary-adrenal axis in the 20-day-old rat: consequences of laboratory weaning. Journal of neuroendocrinology, 14, 450-457.

Shimizu, N.; Yamaguchi, M.; Uesu, K.; Goseki, T. and Abiko, Y. (2000): Stimulation of Prostaglandin E2 and Interleukin-1 Production From Old Rat Periodontal Ligament Cells Subjected to Mechanical Stress. The Journals of Gerontology Series A: Biological Sciences and Medical Sciences, 55, B489-B495.

Thienpont, L.M.; De brabandere, V.I.; Stöckl, D. and De leenheer, A.P. (1994): Development of a new method for the determination of thyroxine in serum based on isotope dilution gas chromatography mass spectrometry. Biological mass spectrometry, 23, 475-482.

Visser, T.J. (2018): Regulation of Thyroid Function, Synthesis, and Function of Thyroid Hormones. Thyroid Diseases: Pathogenesis, Diagnosis, and Treatment, 3-32.

Wu, C.-Y.; Liu, B.; Wang, H.-L. and R\#, D.-Y. (2011): Levothyroxine rescues the leadinduced hypothyroidism and impairment of long-term potentiation in hippocampal CA1 region of the developmental rats. Toxicology and applied pharmacology, 256, 191-197.

Yu, D.; Zhou, H.; Yang, Y.; Jiang, Y.; Wang, T.; LV, L.; Zhou, Q.; Yang, Y.; Dong, X. and HE, J. (2015): The bidirectional effects of hypothyroidism and hyperthyroidism on anxiety-and depression-like behaviors in rats. Hormones and behavior, 69, 106-115.

Zimmermann, M. (1983): Ethical guidelines for investigations of experimental pain in conscious animals. Pain, 16, 109-110.

Zuena, A.R.; Mairesse, J.; Casolini, P.; Cinque, C.; Alema, G.S.; Morley-fletcher, S.; Chiodi, V.; Spagnoli, L.G.; Gradini, R. and Catalani, A. (2008): Prenatal restraint stress generates two distinct behavioral and neurochemical profiles in male and female rats. PloS one, 3, e2170. 


\title{
التأثيرات الفسيولوجية للتعرض للاجهاد حول الولادة على محور الاجهاد العصبى الهرمونى فى صغار الجرذان

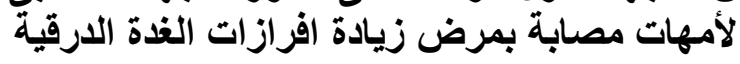

\author{
سطوحى أحد سطوحى ، خالد أحسد عبل الساتر ، محد عبد العزيز محمود

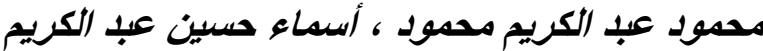

Email: asmaah7592@gmail.com_Assiut University web-site: www.aun.edu.eg

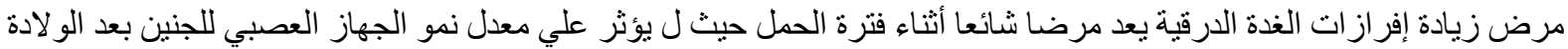

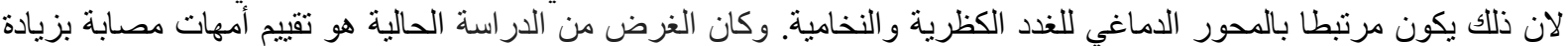

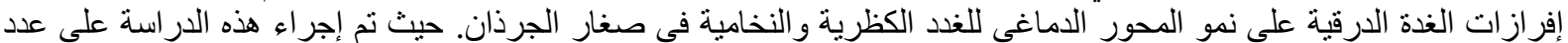

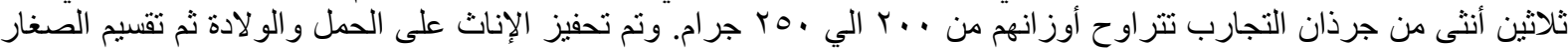

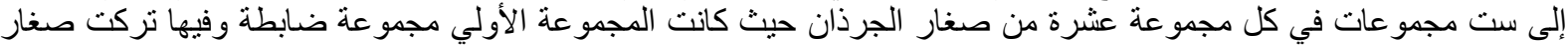

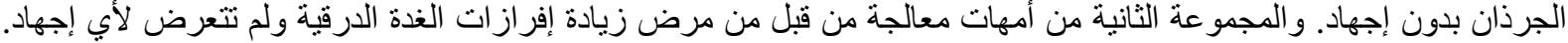

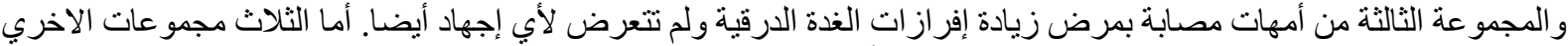

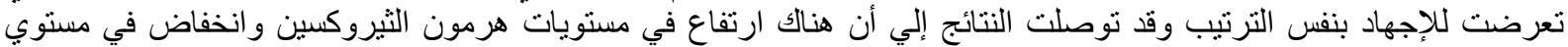

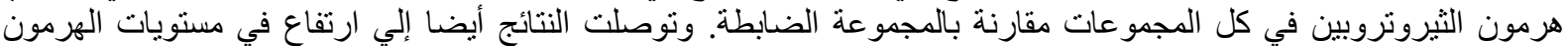

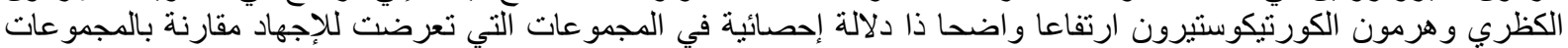

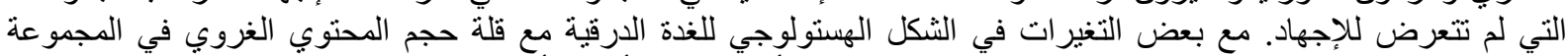

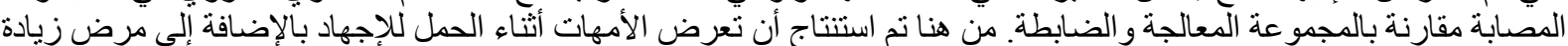

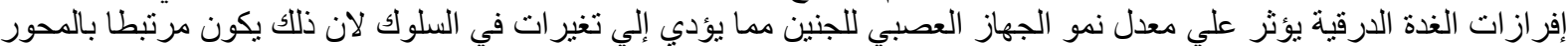

الاماغي للغدد الكظرية والنخامية. 